\title{
EVIDÊNCIAS ACERCA DO AGRESSOR EM CASOS DE VIOLÊNCIA CONTRA O IDOSO: REVISÃO INTEGRATIVA
}

\author{
EVIDENCE ON AGGRESSORS IN CASES \\ OF VIOLENCE AGAINST OLDER PEOPLE: \\ AN INTEGRATIVE REVIEW
}

\section{EVIDENCIAS SOBRE EL AGRESOR EN CASOS DE VIOLENCIA CONTRA EL ANCIANO: REVISIÓN INTEGRATIVA}

\author{
Miriam Fernanda Sanches Alarcon ${ }^{1}$ \\ Daniela Garcia Damaceno ${ }^{2}$ \\ Viviane Boacnin Yoneda Sponchiado ${ }^{3}$ \\ Luzmarina Aparecida Doretto Braccialli ${ }^{4}$ \\ Maria José Sanches Marin 5
}

Como citar este artigo: Alarcon MFS, Damaceno DG, Sponchiado VBY, Braccialli LAD, Marin MJS. Evidências acerca do agressor em casos de violência contra o idoso: revisão integrativa. Rev baiana enferm. 2019;33:e28184.

Objetivo: identificar, nas produções nacionais e internacionais, as evidências acerca do agressor em casos de violência contra o idoso. Método: revisão integrativa da literatura realizada em 2018 nas bases de dados CINAHL, PubMed, Scopus, LILACS, Web of Science e SciELO. Os descritores não controlados (palavras-chave) foram: "Older people", "Sênior", "Elderly" e "Aggressor" e os descritores controlados (Descritores em Ciências da Saúde-DECS): "Violence" e "Aged". Foi realizada leitura seletiva de 238 artigos e 56 teses e dissertações e permaneceram no estudo três artigos e seis dissertações e teses. Resultados: predominou a abordagem qualitativa, com baixo nível de evidência. Os principais abusadores são os filhos que, na maioria das vezes, relataram arrependimento dos seus atos, sendo o fator desagregador mais comum para tais atos o uso de álcool e drogas, desemprego, histórico de violência familiar, proximidades entre agressor e vítima e a dependência financeira de uma das partes. Conclusão: as evidências acerca do agressor em casos de violência contra o idoso, nas produções nacionais e internacionais, limitaram-se ao seu perfil, ao tipo de violência praticada e aos seus sentimentos frente ao ato de violência.

Descritores: Agressão. Idoso. Pessoas idosas.

Objective: to identify evidence on aggressors in cases of violence against older people in national and international studies. Method: an integrative literature review was carried out in 2018 in the CINAHL, PubMed, Scopus, LILACS, Web of Science, and SciELO databases. The non-controlled descriptors (keywords) were: "Older people", "Senior", "Elderly", and "Aggressor". The controlled descriptors (Health Sciences Descriptors-DeCS) were: "Violence" and "Aged". After close reading of 238 articles and 56 theses and dissertations, three articles and six dissertations and theses were

\footnotetext{
Enfermeira. Mestre em Ensino em Saúde. Professora Assistente da Universidade Estadual do Norte do Paraná. Bandeirantes, Paraná, Brasil. miriam@uenp.edu.br Enfermeira. Mestre em Saúde e Envelhecimento. Universidade Estadual Paulista "Júlio de Mesquita Filho", Unesp. Botucatu, São Paulo, Brasil.

Delegada. Mestre em Teoria do Direito e do Estado. Delegada de Polícia Civil do Estado de São Paulo. Marília, São Paulo, Brasil.

Enfermeira. Doutora em Ciências. Docente da Faculdade de Medicina de Marília. Marília, São Paulo, Brasil.

Enfermeira. Doutora em Enfermagem Fundamental. Docente da Faculdade de Medicina de Marília. Marília, São Paulo, Brasil.
} 
selected. Results: a prevalence of the qualitative approach with low evidence level was found. The main aggressors found were older people's children, who mostly reported repentance for their acts, which were often caused by alcohol and drug use, unemployment, history of family violence, closeness between aggressors and victims, and financial dependence on one of the parties. Conclusion: evidence on aggressors in cases of violence against older people in national and international studies was limited to their profile, type of violence practiced, and feelings regarding the act of violence.

Descriptors: Aggression. Aged. Older people.

Objetivo: identificar, en la producción nacional e internacional, evidencias sobre el agresor en casos de violencia contra el anciano. Método: revisión integrativa de literatura, realizada durante 2018 en las bases CINAHL, PubMed, Scopus, LILACS, Web of Science y SciELO. Fueron descriptores no controlados (palabras clave): "Older people" "Senior", "Elderly" y "Aggressor"; y descriptores controlados (Descriptores en Ciencias de la Salud-DeCS): "Violence" y "Aged". Se practicó lectura selectiva de 238 artículos y 56 tesis y disertaciones. Fueron seleccionados 3 artículos y 6 disertaciones y tesis. Resultados: predominó abordaje cualitativo, con bajo nivel de evidencia. Los hijos resultaron ser los principales abusadores, habiendo manifestado, mayoritariamente, arrepentimiento. Los actos disparadores más habituales fueron: consumo de alcohol y drogas, desempleo, historial de violencia familiar, cercanía entre agresor y victima y dependencia financiera de una parte. Conclusión: las evidencias sobre el agresor en casos de violencia contra el anciano, en producciones nacionales e internacionales, solo describieron perfiles, tipos de violencia aplicada y sentimientos ante el acto de violencia.

Descriptores: Agresión. Anciano. Personas de Edad.

\section{Introdução}

O crescente envelhecimento populacional, embora considerado uma importante conquista da humanidade, tem apresentado consequências, a exemplo da violência contra a pessoa idosa. Esse tema, presente no cotidiano das pessoas e das famílias, tem se tornado de grande relevância para a saúde pública, devido ao impacto causado na qualidade de vida dos envolvidos na situação ${ }^{(1)}$.

Trata-se de uma condição de difícil manejo, visto que as dificuldades iniciam-se na própria investigação, isto é, na confirmação dos casos, uma vez que a maioria ocorre no domicílio, dentro da própria família, levando o agredido a ter medo e vergonha de denunciar. Tem-se a constatação de que a cada quatro idosos vítimas de violência apenas um registra o caso ${ }^{(2)}$.

Estudo multicêntrico realizado com 1.995 idosos, na faixa etária de 65 anos ou mais, no Canadá, Colômbia, Brasil e na Albânia, concluiu que 0,63-0,85\% dos participantes sofreram violência física e 3,2-23,5\%, violência psicológica $^{(3)}$. As consequências dessa violência incluem traumas físicos, que podem gerar incapacidade, sofrimento, problemas psicoemocionais, danos morais e até mesmo a morte ${ }^{(4)}$.

Em uma revisão sistemática foi evidenciado que a violência é prevalente em todo o mundo e que os idosos vítimas de abuso e negligência correm maior risco de morrer do que aqueles que não sofrem violência ${ }^{(5)}$.

No Brasil, a situação do idoso não difere dos demais países, uma vez que eles sofrem preconceitos e discriminação e as denúncias de maus-tratos e negligência são mais frequentes em organizações de assistência social e saúde. Entretanto, é no ambiente doméstico que a maior parte dos abusos acontecem. Nele, o idoso geralmente está isolado, deprimido e, quando agredido, sente-se acuado com medo de denunciar o agressor e sofrer maus-tratos consequentes, tornando-se, assim, um círculo vicioso de agressões e medos ${ }^{(6)}$.

Frente ao exposto, tem-se a constatação de que a condição de vulnerabilidade dos idosos nos aspectos físico, social, econômico e emocional leva-os a sofrer a violência e suas consequências. As intervenções, entretanto, demandam a compreensão do contexto em que 
eles estão inseridos. Dessa forma, embora a convivência com os agressores traga riscos a esses idosos, esse cenário mostra-se como única opção de sobrevivência para eles.

Nesse contexto, surge o seguinte questionamento: Qual o conhecimento produzido e o seu nível de evidência acerca do agressor em casos de violência contra o idoso? Este estudo teve como objetivo identificar, nas produções nacionais e internacionais, as evidências acerca do agressor em casos de violência contra o idoso.

\section{Método}

Trata-se uma revisão integrativa da literatura, compreendida como um método que permite a construção da discussão em relação aos métodos e resultados das publicações, visando a análise do conhecimento pré-existente sobre o tema investigado $^{(7)}$. Esse tipo de método permite ainda a sistematização de estudos com metodologias diferentes e a síntese dos resultados obtidos, prezando pelo rigor científico ${ }^{(8)}$.

O ponto de partida do estudo foi a identificação dos aspectos sinalizados pela estratégia PICO, acrônimo para P: Paciente ou população investigada; I: Intervenção ou indicador do que será investigado; C: Comparação ou controle como critérios para avaliação da efetividade da intervenção ou da questão de interesse; O: Outcome (desfecho) que é a resposta obtida ${ }^{(9)}$. Neste estudo, tal estratégia foi empregada da seguinte forma: P: Agressores; I: Ter cometido violência contra o idoso; C: Não se aplica; O: Evidência acerca do agressor.

A busca dos estudos teve início em maio de 2018 e contou com descritores não controlados (palavras-chave) - "Older people", "Sênior", "Elderly" e "Aggressor" - e descritores controlados
(Descritores em Ciências da Saúde-DECS) "Violence" e "Aged". As bases de dados utilizadas foram: Literatura Latino-Americana e do Caribe em Ciências da Saúde (LILACS); Cumulative Index to Nursing and Allied Health Literature (CINAHL); SCOPUS; Web of Science, US National Library of medicine (PUBMED) e Scientific Eletronic Library (SciELO).

Adotou-se como critérios de inclusão: artigos primários que apresentavam informações acerca dos agressores de idosos, publicados no período de 2008 a 2018, nos idiomas inglês, português ou espanhol e com texto completo disponível. A delimitação temporal foi motivada pelo interesse das investigadoras em explorar as caracteristicas que envolvem os agressores e suas relações com suas vítimas no tempo presente. Os critérios de exclusão foram: editorais, artigos de revisão, aqueles já selecionados na busca em outra base de dados e que não respondiam à questão da pesquisa.

Para as dissertações e teses foi utilizado o acervo eletrônico de duas bibliotecas digitais: Biblioteca Digital Brasileira de Teses e Dissertações (BDTD) e portal da Coordenação de Aperfeiçoamento de Pessoal de Nível Superior (CAPES). Utilizou-se como palavras-chave do banco de dissertações e teses da Capes, os termos "Agressor" e "Idoso"; na BDTD, "Violência", "Idoso" e "Agressor". Foram utlizados os seguintes critérios de inclusão: artigos originais, teses e dissertações disponíveis on-line na íntegra. Foram critérios de exclusão: artigos de revisão bibliográfica e reflexão teórica.

Inicialmente foi realizada a leitura seletiva de 238 artigos e 56 teses/dissertações. Seguindo o Fluxograma 1, permaneceram na amostra final 3 artigos e 6 dissertações/teses. 
Fluxograma 1 - Seleção amostral das publicações sobre evidências acerca do agressor em casos de violência contra o idoso. Marília, São Paulo, Brasil - 2018

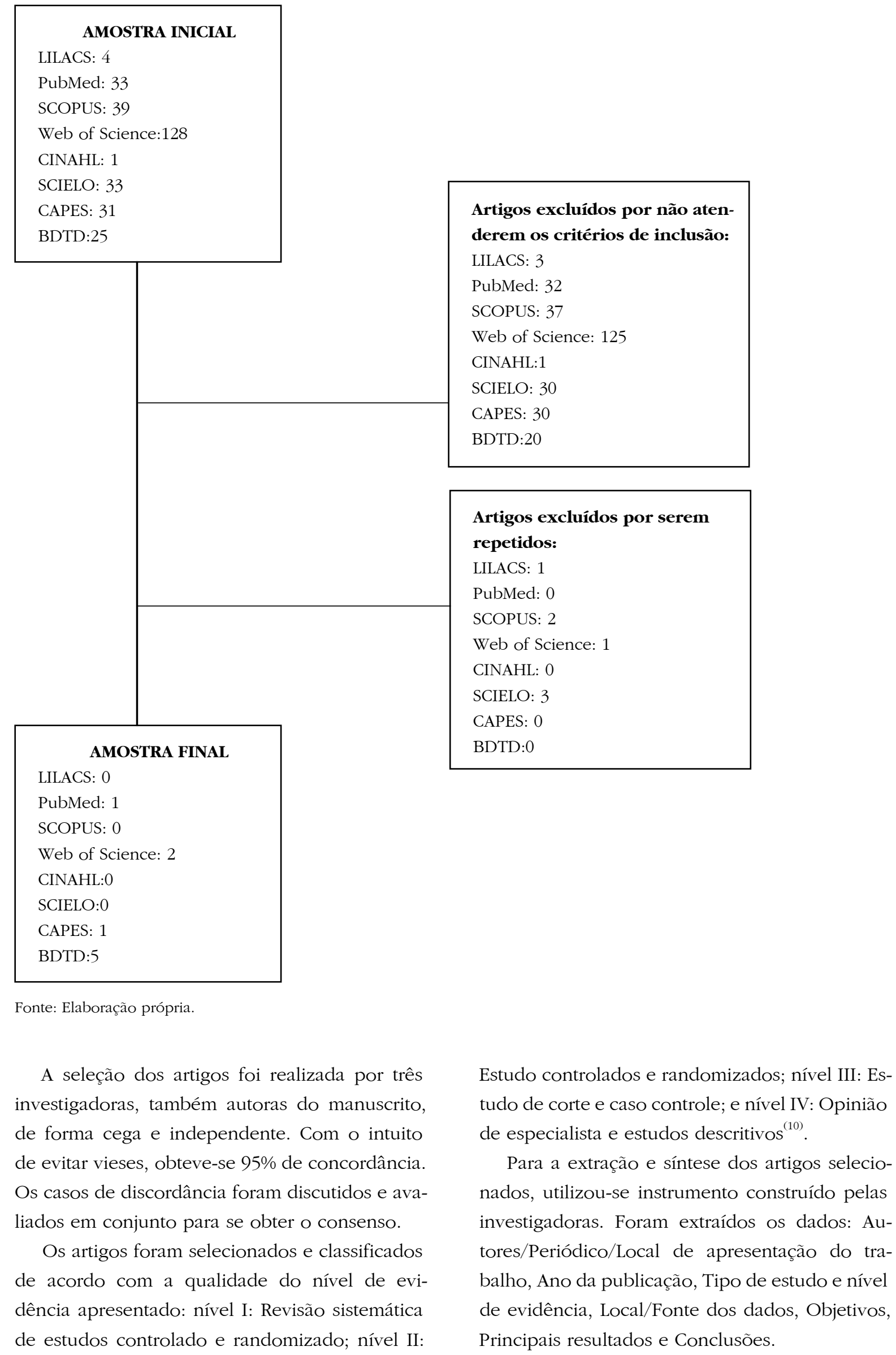


A apresentação dos dados foi sistematizada em forma de quadro e a análise crítica e síntese reflexiva foram realizadas de forma descritiva segundo os achados acerca dos agressores de idosos.

\section{Resultados e Discussão}

A amostra do estudo foi composta por três artigos, três teses e três dissertações, sendo um estudo de 2014, sete de 2016 e um de 2017, todos realizados no Brasil.

No delineamento metodológico, encontrou-se: um estudo de delineamento ecológico, dois estudos descritivos com abordagem qualitativa, um estudo descritivo com abordagem quantitativa, três estudos retrospectivos, um estudo de base populacional de caráter descritivo e um estudo exploratório de caráter qualitativo. A maioria, portanto, encontra-se no Nível de Evidências grau IV seguido do Grau II. Os participantes das pesquisas foram os agressores de idosos e os próprios idosos.

O Quadro 1 aborda as características e os principais achados das publicações analisadas de acordo com: Autores/Ano/Periódico ou Local de apresentação, tipo de pesquisa e nível de evidência/Local de realização/Fonte dos dados e Objetivos. O Quadro 2 apresenta: Autores/Ano/ Periódico ou Local de apresentação, principais resultados e Conclusões.

Quadro 1 - Síntese dos artigos publicados sobre evidências acerca do agressor em casos de violência contra o idoso.

(continua)

\begin{tabular}{|c|c|c|}
\hline $\begin{array}{l}\text { Autores/ Ano/ } \\
\text { Periódico ou Local } \\
\text { de apresentação }\end{array}$ & $\begin{array}{l}\text { Tipo de pesquisa e nível de } \\
\text { evidência/ Local /Fonte }\end{array}$ & Objetivos \\
\hline $\begin{array}{l}\text { Irigaray TQ, Esteves CS, } \\
\text { Pacheco JTB, Grassi- } \\
\text { Oliveira R, Argimon } \\
\text { IIL }^{(9)} \\
2016 . \\
\text { Estud. psicol. } \\
\text { (Campinas) }\end{array}$ & $\begin{array}{l}\text { Tipo: Estudo documental e retrospectivo } \\
\text { Nível de evidência: IV } \\
\text { Local: Delegacia de Proteção ao Idoso } \\
\text { Fonte dos dados: Boletim de idosos que } \\
\text { sofreram maus tratos. }\end{array}$ & $\begin{array}{l}\text { Verificar a prevalência e os tipos } \\
\text { de maus-tratos sofridos por idosos } \\
\text { registrados na Delegacia de } \\
\text { Proteção ao Idoso do município de } \\
\text { Porto Alegre (RS). } \\
\text { Descrever o perfil da vítima e do } \\
\text { agressor e identificar o motivo da } \\
\text { ocorrência. }\end{array}$ \\
\hline $\begin{array}{l}\text { Rodrigues RAP, } \\
\text { Monteiro EA, Santos } \\
\text { AMR, Pontes MLF, Fhon } \\
\text { JRS, Bolina AF, et } \mathrm{al}^{(12)} \\
2017 . \\
\text { Rev. Bras. Enferm. }\end{array}$ & $\begin{array}{l}\text { Tipo: Estudo com delineamento ecológico, } \\
\text { do tipo série histórica. } \\
\text { Nível de evidência: IV } \\
\text { Local: Delegacias do idoso de Ribeirão } \\
\text { Preto, João Pessoa e Teresina. } \\
\text { Fonte dos dados: Boletim de ocorrência de } \\
\text { idosos que sofreram violência. }\end{array}$ & $\begin{array}{l}\text { Identificar características } \\
\text { sociodemográficas das vítimas e dos } \\
\text { agressores, tipo de violência, local, } \\
\text { bem como comparar as taxas em três } \\
\text { municípios brasileiros no período de } \\
2009 \text { a } 2013 .\end{array}$ \\
\hline $\begin{array}{l}\text { Faustino } \mathrm{AM}^{(13)} \\
2014 . \\
\text { Tese } \\
\text { Universidade de } \\
\text { Brasília }\end{array}$ & $\begin{array}{l}\text { Tipo: Estudo de base populacional, de } \\
\text { caráter descritivo } \\
\text { Nível de evidência: IV } \\
\text { Local: Centro de Saúde. } \\
\text { Fonte: A amostra foi composta por } 237 \\
\text { idosos, com idade entre } 60 \text { e } 93 \text { anos. }\end{array}$ & $\begin{array}{l}\text { Caracterizar os idosos quanto aos } \\
\text { aspectos sociodemográficos, condições } \\
\text { de saúde, informações pessoais e } \\
\text { a sua relação com as naturezas de } \\
\text { violência psicológica, física, financeira, } \\
\text { abandono, negligência, autonegligência. } \\
\text { Caracterizar o tipo de agressor e } \\
\text { a frequência dos atos de violência } \\
\text { sofridos pelos idosos. } \\
\text { Analisar a prevalência de casos de } \\
\text { violência, segundo as situações de } \\
\text { violência. } \\
\text { Identificar a relação entre a capacidade } \\
\text { funcional e cognitiva do idoso e a } \\
\text { presença de violência. }\end{array}$ \\
\hline
\end{tabular}


Quadro 1 - Síntese dos artigos publicados sobre evidências acerca do agressor em casos de violência contra o idoso.

\begin{tabular}{|c|c|c|}
\hline $\begin{array}{l}\text { Autores/ Ano/ } \\
\text { Periódico ou Local } \\
\text { de apresentação }\end{array}$ & $\begin{array}{l}\text { Tipo de pesquisa e nível de } \\
\text { evidência/Local /Fonte }\end{array}$ & Objetivos \\
\hline $\begin{array}{l}\text { Bohm V } \mathrm{V}^{(14)} \\
2016 . \\
\text { Tese } \\
\text { Universidade Federal } \\
\text { do Rio Grande do Sul }\end{array}$ & $\begin{array}{l}\text { Tipo: Pesquisa qualitativa. } \\
\text { Nível de evidência: IV. } \\
\text { Local: Município de Caxias do Sul, RS } \\
\text { Fonte: Amostra constituída por } \\
\text { conveniência, sendo os agressores } 5 \\
\text { mulheres e } 3 \text { homens, todos filhos, exceto } \\
\text { um que era marido. }\end{array}$ & $\begin{array}{l}\text { Analisar os fatores que conduziram } \\
\text { à violência contra as pessoas idosas } \\
\text { através da perspectiva dos agressores. } \\
\text { Conhecer as histórias de vida dos } \\
\text { agressores de idosos. } \\
\text { Identificar os possíveis gatilhos que } \\
\text { desencadearam as agressões. } \\
\text { Compreender os aspectos estruturais } \\
\text { que possam ter relações com a prática } \\
\text { da violência. } \\
\text { Oferecer elementos para intervenções } \\
\text { educativas no campo da violência. }\end{array}$ \\
\hline $\begin{array}{l}\text { Taveira } L^{(15)} \\
2016 . \\
\text { Dissertação } \\
\text { Universidade Católica } \\
\text { de Brasília }\end{array}$ & $\begin{array}{l}\text { Tipo: Estudo quantitativo, descritivo, } \\
\text { retrospectivo, com recorte transversal } \\
\text { Nível de evidência: IV } \\
\text { Local: Secretária de direitos humanos da } \\
\text { Presidência da República. } \\
\text { Fonte: Banco informatizado dos dados, } \\
\text { sendo vítimas do sexo feminino e } \\
\text { masculino. }\end{array}$ & $\begin{array}{l}\text { Analisar o perfil da violência contra os } \\
\text { idosos no Brasil a partir de denúncias } \\
\text { registradas no disque } 100 \text {, descrevendo } \\
\text { aspecto sociodemográfico da vítima, } \\
\text { identificando a incidência da violência } \\
\text { por região geográfica brasileira e o tipo } \\
\text { de vínculo do agressor suspeito com o } \\
\text { padecente. }\end{array}$ \\
\hline $\begin{array}{l}\text { Cachina AMP } \\
2016 . \\
\text { Dissertação } \\
\text { Universidade Federal } \\
\text { do Rio Grande do } \\
\text { Norte }\end{array}$ & $\begin{array}{l}\text { Tipo: Análise documental } \\
\text { Nível de evidência: IV } \\
\text { Local: Ministério Público do Rio Grande do } \\
\text { Norte. } \\
\text { Fonte: Denúncias de maus-tratos em idosos. }\end{array}$ & $\begin{array}{l}\text { Analisar os processos referentes } \\
\text { às denúncias que chegaram às } \\
\text { promotorias de justiça especializadas } \\
\text { na matéria do idoso. Delimitar o perfil } \\
\text { dos participantes. }\end{array}$ \\
\hline $\begin{array}{l}\text { Lopes LGF }{ }^{(17)} \\
2016 . \\
\text { Dissertação } \\
\text { Universidade Federal } \\
\text { de Pernambuco. }\end{array}$ & $\begin{array}{l}\text { Tipo: Estudo descritivo, quantitativo, de } \\
\text { corte transversal. } \\
\text { Nivel de evidência: IV } \\
\text { Local: Dados do SINAN } \\
\text { Fonte: Indivíduos com } 60 \text { anos ou mais que } \\
\text { sofreram violência. }\end{array}$ & $\begin{array}{l}\text { Avaliar a ocorrência da violência } \\
\text { sofrida pela idosa em Caruaru/PE. } \\
\text { Caracterizar o perfil do agressor } \\
\text { segundo as variáveis: sexo, vínculo } \\
\text { com a pessoa idosa e suspeita do uso } \\
\text { de álcool. } \\
\text { Caracterizar a amostra vítima de } \\
\text { violência, segundo as variáveis } \\
\text { demográficas. } \\
\text { Descrever a violência segundo } \\
\text { natureza, local e grau da lesão } \\
\text { instrumento utilizado. } \\
\text { Verificar a evolução dos casos, } \\
\text { considerando alta hospitalar, evasão/ } \\
\text { fuga e óbitos. } \\
\text { Verificar se houve associação entre a } \\
\text { ocorrência da violência e as variáveis } \\
\text { investigadas. }\end{array}$ \\
\hline $\begin{array}{l}\text { Siqueira } \mathrm{ACBS}^{(18)} \\
2016 . \\
\text { Tese }\end{array}$ & $\begin{array}{l}\text { Tipo: Pesquisa quantiqualitativa } \\
\text { Nível de evidência: IV } \\
\text { Local: Instituições que atuam na proteção } \\
\text { dos idosos na cidade de Teresina: } \\
\text { Delegacia especializada do idoso, Ministério } \\
\text { Público, Defensoria Pública, espaços físicos } \\
\text { de atendimento às pessoas idosas. } \\
\text { Fonte: Idosos vítimas de violência }\end{array}$ & $\begin{array}{l}\text { Analisar os fatores ou condições que } \\
\text { podem influenciar no comportamento } \\
\text { do cuidador ou parente da vítima, a } \\
\text { ponto de levá-lo a praticar violência } \\
\text { contra o idoso que está sob seus } \\
\text { cuidados. }\end{array}$ \\
\hline
\end{tabular}

Fonte: Elaboração própria. 
Quadro 1 - Síntese dos artigos publicados sobre evidências acerca do agressor em casos de violência contra o idoso.

(continua)

\begin{tabular}{|c|c|c|}
\hline $\begin{array}{c}\text { Autores/ Ano/ } \\
\text { Periódico ou Local } \\
\text { de apresentação }\end{array}$ & Principais resultados & Conclusões \\
\hline $\begin{array}{l}\text { Irigaray TQ, Esteves CS, } \\
\text { Pacheco JTB, Grassi- } \\
\text { Oliveira R, Argimon } \\
\text { IIL }^{(9)} \\
2016 . \\
\text { Estud. psicol. } \\
\text { (Campinas) }\end{array}$ & $\begin{array}{l}\text { Dos } 224 \text { boletins de ocorrência, } 175 \\
\text { denunciavam situações de maus-tratos, } \\
\text { sendo psicológicos os mais frequentes, } \\
\text { seguidos pelo abuso financeiro. A vítima, } \\
\text { na maioria dos casos, foi do sexo feminino } \\
\text { e de baixa escolaridade. O agressor era } \\
\text { geralmente do sexo masculino e familiar } \\
\text { da vítima. No estudo foram encontradas } \\
\text { agressões verbais e físicas. As principais } \\
\text { motivações foram: álcool, proximidade } \\
\text { física, dependência financeira do agressor } \\
\text { com o idoso e relacionamento de violência } \\
\text { entre ambos. Os sentimentos do agressor } \\
\text { após a ocorrência foram: tristeza, decepção, } \\
\text { raiva, sentimento de injustiça, angústia e } \\
\text { revolta; as necessidades relacionam-se ao } \\
\text { desejo de encerrar o processo e voltar ao } \\
\text { bom convívio com o idoso. }\end{array}$ & $\begin{array}{l}\text { É necessária a realização de novos } \\
\text { estudos com uma abrangência maior, } \\
\text { que permita informações junto a } \\
\text { idosos da comunidade e não somente } \\
\text { em boletins de ocorrência, a fim de } \\
\text { se obter maior conhecimento sobre } \\
\text { o tema e elaborar estratégias de } \\
\text { prevenção e intervenção. É necessário } \\
\text { maior visibilidade do agressor com } \\
\text { a finalidade de compreender o que } \\
\text { desencadeou a violência e contribuir } \\
\text { para que esses possam dar um novo } \\
\text { significado à experiência, por meio de } \\
\text { acolhimento de uma escuta sensível. }\end{array}$ \\
\hline $\begin{array}{l}\text { Rodrigues RAP, } \\
\text { Monteiro EA, Santos } \\
\text { AMR, Pontes MLF, Fhon } \\
\text { JRS, Bolina AF, et al }{ }^{(12)} \\
2017 \text {. } \\
\text { Rev. Bras. Enferm. }\end{array}$ & $\begin{array}{l}\text { Na maioria dos casos, predominou a } \\
\text { violência psicológica, que ocorreu na } \\
\text { própria residência. Nos idosos mais jovens, } \\
\text { as taxas são semelhantes entre } \\
\text { os sexos. Nos três municípios, } \\
\text { predominaram agressores com idade } \\
\text { entre } 30 \text { e } 49 \text { anos do sexo masculino. } \\
\text { Verificou-se que os agressores consumiram } \\
\text { álcool e drogas em baixa proporção. Em } \\
\text { Ribeirão Preto, a maioria dos agressores } \\
\text { eram solteiros, familiares e não residiam } \\
\text { na mesma casa. Em João Pessoa, a maioria } \\
\text { dos agressores eram casados, familiares } \\
\text { da vítima e não residiam com o idoso. Em } \\
\text { Teresina, predomínio de agressor solteiro, } \\
\text { família que residia com a vítima. }\end{array}$ & $\begin{array}{l}\text { A violência é um fenômeno cultural de } \\
\text { difícil notificação pelo próprio idoso, } \\
\text { pois geralmente ocorre no contexto } \\
\text { familiar. }\end{array}$ \\
\hline $\begin{array}{l}\text { Faustino AM } \\
2014 . \\
\text { Tese } \\
\text { Universidade de } \\
\text { Brasília }\end{array}$ & $\begin{array}{l}\text { Quanto à prevalência, 64,97\% dos idosos } \\
\text { relatou ter sofrido pelo menos um tipo de } \\
\text { violência. } \\
\text { Quanto ao tipo de agressor, os filhos, } \\
\text { seguidos dos cônjuges foram os mais } \\
\text { citados. O abandono foi o tipo de violência } \\
\text { mais relatado pelo idoso. As variáveis } \\
\text { sociodemográficas e de avaliação da } \\
\text { capacidade funcional e cognitiva estão } \\
\text { relacionadas com as situações de violência. } \\
\text { O agressor é um membro da família. Ser } \\
\text { dependente em atividades básicas de } \\
\text { autocuidado favorece ao aumento da } \\
\text { exposição à situação de maus-tratos físicos. } \\
\text { Em relação à violência e função cognitiva, } \\
\text { no estudo não houve relação estatística, } \\
\text { porém as maiores frequências de violência } \\
\text { foram relatadas por idosos com pior } \\
\text { desempenho cognitivo. }\end{array}$ & $\begin{array}{l}\text { O fato de os familiares, com destaque } \\
\text { para filhos e cônjuges, serem os } \\
\text { principais agressores, torna latentes } \\
\text { os conflitos geracionais e as relações } \\
\text { íntimas. } \\
\text { Os idosos também declararam ter } \\
\text { vivenciado as situações de violências } \\
\text { do tipo psicológica, abandono e } \\
\text { negligência, sendo as de maior } \\
\text { percentual, pelo menos cinco ou mais } \\
\text { vezes. }\end{array}$ \\
\hline
\end{tabular}


Quadro 1 - Síntese dos artigos publicados sobre evidências acerca do agressor em casos de violência contra o idoso.

(conclusão)

\begin{tabular}{|c|c|c|}
\hline $\begin{array}{c}\text { Autores/ Ano/ } \\
\text { Periódico ou Local } \\
\text { de apresentação }\end{array}$ & Principais resultados & Conclusões \\
\hline $\begin{array}{l}\text { Bohm V } \\
2016 . \\
\text { Tese } \\
\text { Universidade Federal } \\
\text { do Rio Grande do Sul }\end{array}$ & $\begin{array}{l}\text { Os agressores, geralmente filhos e netos, } \\
\text { na maioria das vezes foram vítimas de } \\
\text { violência em outras fases da vida. O } \\
\text { despertar para a ocorrência da violência } \\
\text { está relacionado à desestrutura familiar, } \\
\text { desemprego e consumo abusivo de álcool/ } \\
\text { drogas. Identificou-se atuação precária dos } \\
\text { mecanismos sociais de proteção aos idosos, } \\
\text { que não conseguiam garantir-lhes proteção. }\end{array}$ & $\begin{array}{l}\text { A violência psicológica não é admitida } \\
\text { como gravidade pelos agressores, } \\
\text { sendo normal para eles, pois não } \\
\text { prejudica a vítima. }\end{array}$ \\
\hline $\begin{array}{l}\text { Taveira LM }{ }^{(15)} \\
2016 . \\
\text { Dissertação } \\
\text { Universidade Católica } \\
\text { de Brasília }\end{array}$ & $\begin{array}{l}\text { O maior percentual das vítimas é do sexo } \\
\text { feminino. A pesquisa identificou que } \\
\text { a maior incidência da violência foi na } \\
\text { região Sudeste. Os filhos são os principais } \\
\text { suspeitos de cometer agressão e, na } \\
\text { sequência, os netos. }\end{array}$ & $\begin{array}{l}\text { O estudo constatou o aumento de } \\
\text { registro de violência e confirmou a } \\
\text { existência de várias formas de violência } \\
\text { familiar contra a pessoa idosa. O } \\
\text { tipo de denúncia mais frequente foi } \\
\text { a negligência, e isso sugere a falta } \\
\text { de informação e de capacitação } \\
\text { adequada da família para o cuidado e o } \\
\text { fortalecimento de vínculos. }\end{array}$ \\
\hline $\begin{array}{l}\text { Cachina AMP } \\
2016 . \\
\text { Dissertação } \\
\text { Universidade Federal } \\
\text { do Rio Grande do } \\
\text { Norte }\end{array}$ & $\begin{array}{l}\text { As violências mais apontadas foram } \\
\text { negligência seguida de violência física, } \\
\text { psicológica, financeira, abandono e } \\
\text { autonegligência. As mulheres são mais } \\
\text { vítimas que os homens. Os familiares foram } \\
\text { identificados como violadores, sendo a } \\
\text { maioria os filhos homens. }\end{array}$ & $\begin{array}{l}\text { Observou-se que as denúncias } \\
\text { por parte dos serviços de saúde } \\
\text { expressaram-se timidamente, o } \\
\text { que demonstra a necessidade de } \\
\text { investimento na comunicação entre os } \\
\text { serviços. }\end{array}$ \\
\hline $\begin{array}{l}\text { Lopes LGF } \\
2016 . \\
\text { Dissertação } \\
\text { Universidade Federal } \\
\text { de Pernambuco. }\end{array}$ & $\begin{array}{l}\text { Foram notificados } 231 \text { casos de violência } \\
\text { em Caruaru (PE) no período de } 2009 \\
\text { a } 2015 \text {. Houve predomínio do sexo } \\
\text { masculino, e faixa etária de } 60-69 \text { anos. Os } \\
\text { casados sofreram mais violência. O local } \\
\text { de maior ocorrência foram as residências e } \\
\text { a violência física predominou. }\end{array}$ & $\begin{array}{l}\text { Sendo um estudo inédito na cidade } \\
\text { de Caruaru, os dados apresentados } \\
\text { poderão servir de base para realização } \\
\text { de intervenções necessárias em nível de } \\
\text { promoção e prevenção da saúde com } \\
\text { o intuito de garantir mais qualidade de } \\
\text { vida. }\end{array}$ \\
\hline $\begin{array}{l}\text { Siqueira ACBS } \\
2016 . \\
\text { Tese } \\
\text { Universidade Federal } \\
\text { da Paraíba }\end{array}$ & $\begin{array}{l}\text { As mulheres idosas foram vitimadas mais } \\
\text { que os homens. O grau de parentesco } \\
\text { que mais predominou como agressor foi } \\
\text { o de filhas, porém, em alguns delitos, os } \\
\text { homens foram os que mais agrediram. O } \\
\text { uso de drogas e de álcool foram os fatores } \\
\text { desencadeadores da violência por parte } \\
\text { dos cuidadores masculinos. }\end{array}$ & $\begin{array}{l}\text { A violência provocada pelo cuidador } \\
\text { contra o idoso pode ser causada por } \\
\text { fatores como estresse, uso de drogas } \\
\text { e de álcool, isolamento social e/ou } \\
\text { certeza da impunidade. Portanto, } \\
\text { fatores psíquicos, sociais e/ou jurídicos } \\
\text { podem causar o não reconhecimento } \\
\text { do idoso-vítima. }\end{array}$ \\
\hline
\end{tabular}

Fonte: Elaboração própria.

No que se refere ao perfil do agressor do idoso, os principais abusadores foram os familiares, com predominância dos filhos homens, seguidos dos cônjuges ou companheiros, além de outros, como noras, genros e netos ${ }^{(13,16)}$. Outra pesquisa evidenciou que, após os filhos, os netos ocupavam a segunda posição ${ }^{(15)}$.
Nesse contexto, constatou-se que os agressores eram usuários de drogas ilícitas e de álcool em excesso, fatores considerados de potencialização da agressividade e de maus-tratos ${ }^{(11,18)}$. O fato de o agressor residir na casa do idoso e ser o cuidador informal ${ }^{(18)}$, estar desempregado, dependendo financeiramente da vítima para 
conseguir dinheiro e suprir suas necessidades configuraram-se fatores que desencadeavam a $\operatorname{agressividade}^{(14)}$.

Acrescenta-se que o desemprego, como causa isolada, não é condição para a violência, contudo, pode gerar estresse, fragilização da autoestima e provocar a escassez de recursos financeiros, tornando-se, assim, fator de risco para a ocorrência da violência econômica, uma vez que os idosos têm seus recursos garantidos ${ }^{(14)}$.

Aliado ao uso abusivo de drogas e álcool, encontra-se a dependência financeira do agressor em relação ao idoso, bem como o fato de morarem na mesma casa ou no mesmo quintal ${ }^{(19)}$. Deve-se também levar em conta a existência de vínculo afetivo entre o agressor e o idoso, fazendo com que a vítima se cale diante da agressão, com receio de que o outro seja punido ${ }^{(16)}$. Além disso, pode ocorrer entre os idosos vítimas de violência o medo de represálias e de serem internados em um asilo, culpa por gerar um conflito e vergonha da situação. Tal silêncio pode afetar a saúde física e mental do agredido ${ }^{(20)}$.

Constatou-se ainda que os valores conservadores, condicionados e preservados pelos mais velhos foram motivos de questionamentos pelos jovens, os quais quebravam e ameaçavam a autoridade dos idosos, gerando conflitos intergeracionais, o que propicia a ocorrência de diferentes formas de agressão contra os idosos ${ }^{(20)}$.

Quanto aos tipos de violência sofrida incluem-se a psicológica, o abandono ou negligência, o abuso financeiro e a violência física $^{(14,17)}$. Quando se trata da violência psicológica, o agressor a considera mais branda do que a violência física ${ }^{(14)}$. A violência financeira ocorre quando há uma relação de confiança entre a vítima e o agressor. Na maioria dos casos, deu-se quando a pessoa idosa convivia com familiares usuários de drogas e álcool e esses utilizavam a aposentadoria do idoso para sustentar o vício ${ }^{(16)}$. Quanto à violência física, foi comum a recusa do agressor em reconhecê-la, passando a justificar com relatividade.

Em relação ao sentimento do agressor, foi observado que sentiu-se arrependido dos seus atos e, em outros casos, não compreendia o evento como agressão ${ }^{(14)}$. Os agressores sempre demonstravam, entre suas necessidades, a de encerrar rapidamente o processo e voltar a ter sua vida normal, como trabalhar, estudar e ter uma casa. Verificou-se também o desejo de reconciliação com o idoso e que todas as desavenças fossem encerradas, demonstrando, assim, duplicidade de sentimentos com a situação ${ }^{(11)}$.

Evidenciou-se que é preciso considerar o relacionamento familiar em sua totalidade, bem como o histórico de violência, pois a maioria viveu em um ambiente permeado por esse tipo de constrangimento, passando a reproduzir o que recebeu e presenciou ao longo de sua trajetória de vida ${ }^{(11)}$. A falta de preparação dos agressores para o envelhecimento dos pais e de demais parentes também apareceu nas pesquisas ${ }^{(11-13)}$.

O cuidador, em grande parte, não foi preparado e nunca possuiu/demonstrou/autorreferiu a intenção de exercer tal função. Este é um papel que requer constantes cuidados e dedicação, pois exige deixar/abdicar dos próprios afazeres e modo rotineiro de vida, para adentrar e fazer parte da vida de outra pessoa, a qual possui hábitos e desejos totalmente diferentes ${ }^{(18)}$.

Sendo assim, nessa conformação familiar (idoso e cuidador informal também agressor), há a indicação de que, por mais que a agressão ocorra em ambiente familiar, as instâncias relacionadas ao cuidado e à proteção dos idosos, a exemplo de serviços de saúde, rede socioassistencial e a atenção jurídica, devem ser comunicadas, para a tomada de decisão em relação ao agressor, com vistas ao controle da situação, visto que, muitas vezes, elas são repetidas ${ }^{(19)}$.

Vale destacar que o idoso é o integrante mais prejudicado, quando ocorre a desestruturação do ambiente familiar, cabendo ao estado intervir e proteger seus interesses. Entretanto, ainda existe a falta de efetividade de tais serviços, gerando situações complexas e de difícil solução para aqueles que estão na linha de frente desses atendimentos, como é o caso dos profissionais da atenção básica à saúde, dos serviços de atenção social e dos profissionais da área jurídica ${ }^{(21)}$.

Apesar da relevância da compreensão das necessidades dos agressores de pessoas idosas, com 
vistas a estabelecer intervenções apropriadas, na presente revisão foram encontrados poucos estudos que tratam do tema nas bases de dados pesquisadas. Essa escassez de estudos permitiu constatar-se que ainda são poucas as pesquisas que abordam de forma específica a condição do agressor, fato que se configurou como um fator limitante do estudo. Além disso, a maioria das pesquisas analisadas foram classificadas como de grau IV de evidência, demonstrando a necessidade de estudos mais consistentes sobre o tema.

\section{Conclusão}

Com relação aos tipos dos estudos, predominou a abordagem qualitativa, que apresenta baixo nível de evidência. Os estudos analisados indicavam os filhos como principais abusadores. Estes, na maioria das vezes, relatavam arrependimento dos seus atos. O fator desagregador mais comum para tais atos foi o uso de álcool e drogas, o desemprego, o histórico de violência familiar, a proximidade entre agressor e vítima e a dependência de uma das partes, em especial a financeira.

Conclusivamente pode-se afirmar que as evidências acerca do agressor em casos de violência contra o idoso, nas produções pesquisadas, limitaram-se ao seu perfil, ao tipo de violência praticada e aos seus sentimentos frente ao ato de violência, desvelando que se trata de uma condição de forte relação com a estrutura e o funcionamento familiar.

Diante disso, a prevenção da violência contra a pessoa idosa constitui-se em um desafio para os profissionais da área de saúde, dada a dificuldade de identificar os casos para ofertar os cuidados necessários e adotar outras medidas cabíveis. Salienta-se que, nessas situações, é preciso o reconhecimento das necessidades dos agressores, para que sejam adotadas as intervenções mais consistentes, seja dos serviços de saúde, seja de outros setores também envolvidos com a atenção às pessoas idosas.

Dada a complexidade da violência contra os idosos, recomenda-se que sejam realizados mais estudos sobre a temática, com vistas a trazer mais evidências que contribuam para a adoção de medidas que previnam e minimizem as consequências dessa problemática.

\section{Colaborações:}

1. concepção, projeto, análise e interpretação dos dados: Miriam Fernanda Sanches Alarcon, Daniela Garcia Damaceno e Maria José Sanches Marin;

2. redação do artigo e revisão crítica relevante do conteúdo intelectual: Miriam Fernanda Sanches Alarcon, Daniela Garcia Damaceno, Luzmarina Aparecida Doretto Braccialli, Viviane Boacnin Yoneda Sponchiado e Maria José Sanches Marin;

3. aprovação final da versão a ser publicada: Miriam Fernanda Sanches Alarcon, Daniela Garcia Damaceno, Luzmarina Aparecida Doretto Braccialli, Viviane Boacnin Yoneda Sponchiado e Maria José Sanches Marin.

\section{Referências}

1. Lima FDM. Teoria de Betty Neuman no cuidado à pessoa idosa. Rev baiana enferm. 2014 dez;28(3):219-24.

2. Cooper C, Livingston G. Intervening to reduce elder abuse: challenges for research. Age Ageing [Internet]. 2016 [cited 2017 Jan 6];45(2):184-5. Available from: https://academic.oup.com/ageing/ article-lookup/doi/10.1093/ageing/afw007

3. Guedes DT, Alvarado BE, Phillips SP, Curcio CL, Zunzunegui MV, Guerra RO. Socioeconomic status, social relations and domestic violence (DV) against elderly people in Canada, Albania Colombia and Brazil. Arch Gerontol Geriatr [Internet]. 2015 [cited 2017 Feb 2];60:492-500. Available from: http://www.aggjournal.com/ article/S0167-4943(15)00011-4/pdf

4. Pinto FNFR, Barham EJ, Albuquerque PP. Idosos vítimas de violência: fatores sociodemográficos e subsídios para futuras intervenções. Estud pesqui psicol [online]. 2013 [cited 2017 Feb 5];13(3:1159-81. Available from: http:// pepsic.bvsalud.org/scielo.php?script $=$ sci abstract\&pid=S1808-42812013000300018\&lng=es\& nrm=iso 
5. Yan E, Chan KL, Tiwari A. A systematic review of prevalence and risk factors for elder abuse. Trauma Violence Abuse. 2015 Apr [cited 2017 Feb 10];16(2):199-219. DOI: 10.1177/1524838014555033

6. Mirabelli SCS, Lodovici FMM, Silveira NDR, Concone MHVB, Fonseca C. O silêncio que oculta: violência contra a pessoa idosa. Mais 60 - Estudos sobre Envelhecimento. 2015 ago;26(62):52-71.

7. Whittemore $\mathrm{R}$, Knafl $\mathrm{K}$. The integrative review: updated methodology. J Adv Nurs. 2005;52(5):546-53.

8. Soares CB, Hoga LA, Peduzzi M, Sangalet C, Yonekura T, Silva DR. Revisão integrativa: conceitos e métodos utilizados na enfermagem. Rev Esc Enferm USP. 2014;48(2):335-45.

9. Irigaray TQ, Esteves CS, Pacheco JTB, Grassi-Oliveira R, Argimon IIL. Maus-tratos contra idosos em Porto Alegre, Rio Grande do Sul: um estudo documental. Est Psicol (Campinas). 2016 jul/set [cited 2018 Jun 15];33(3):543-51. DOI: https:// dx.doi.org/10.1590/1982-02752016000300017

10. Stillwell SB, Fineout-Overholt E, Melnyk BM, Williamson KM. Evidence-based practice, step by step: searching for the evidence. Am J Nurs. 2010;110(5):41-7.

11. Silva CFS, Dias CMSB. Violência contra idosos na família: motivações, sentimentos e necessidades do agressor. Psicol cienc prof. 2016 set;36(3):637-52.

12. Rodrigues RAP, Monteiro EA, Santos AMR, Pontes MLF, Fhon JRS, Bolina AF, et al. Violência contra idosos em três municípios brasileiros. Rev Bras Enferm [Internet]. 2017 Aug [cited 2018 Jun 29];70(4):783-91. DOI: http://dx.doi. org/10.1590/0034-7167-2017-0114

13. Faustino AM. Violência contra pessoas idosas em uma área metropolitana de Brasília, Paranoá Distrito Federal [tese]. Brasília (DF): Universidade de Brasília; 2014.
14. Bohn V. Violência contra pessoas idosas: narrativas de agressores [tese]. Porto Alegre (RS): Universidade Federal do Rio Grande do Sul; 2016.

15. Taveira LM. Perfil da violência cometida contra a pessoa idosa registrada no disque direitos humanos no período de 2011-2015 no Brasil [dissertação]. Brasília (DF): Universidade Católica de Brasília; 2016.

16. Cachina AMP. O Ministério Público na rede de proteção ao idoso na Cidade de Natal-RN e os encaminhamentos das denúncias de maus tratos [dissertação]. Natal: Universidade Federal do Rio Grande do Norte; 2016.

17. Lopes LGF. Violência contra a pessoa idosa no município de Caruaru/PE [dissertação]. Recife: Universidade Federal de Pernambuco; 2016.

18. Siqueira ACBS. Violência provocada por cuidadores de idosos em Teresina-PI: estudo de caso [tese]. João Pessoa: Universidade Federal da Paraíba; 2016

19. Cachina AMP, Paiva IL, Torres TL. Violência intrafamiliar contra idosos: revisão sistemática. Liber [Internet]. 2016 dic [cited 2018 Aug 22];22(2):980-3. Available from: http://www.scielo.org.pe/scielo.php?script=sci_ arttext\&pid=S1729-48272016000200006\&lng=es\&n $\mathrm{rm}=\mathrm{iso}$

20. Oliveira AAV, Trigueiro DRSG, Fernandes MGM, Silva AO. Maus-tratos a idosos: revisão integrativa da literatura. Rev bras enferm [Internet]. 2013 Feb [cited 2018 Jun 27];66(1):128-33. DOI: http:// dx.doi.org/10.1590/S0034-71672013000100020

21. Pina SCT, Coelho APFC, Torres JC, Teixeira AB. O papel da família e do estado na proteção do idoso. Ciência et praxis (online). 2016 [cited 2018 Aug 20];9(18):35-8. Available from: http://revista.uemg. br/index.php/praxys/article/viewFile/2532/1495

Recebido: 26 de setembro de 2018 Aprovado: 1 de julho de 2019 Publicado: 13 de novembro de 2019

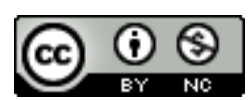

A Revista Baiana de Enfermagem utiliza a Licença Creative Commons - Atribuição-NãoComercial 4.0 Internacional. https://creativecommons.org/licenses/by-nc/4.0/

Este artigo é de acesso aberto distribuído sob os termos da Licença Creative Commons (CC BY-NC). Esta licença permite que outros remixem, adaptem e criem a partir do seu trabalho para fins não comerciais. Embora os novos trabalhos tenham de lhe atribuir o devido crédito e não possam ser usados para fins comerciais, os usuários não têm de licenciar esses trabalhos derivados sob os mesmos termos. 